\title{
MASS BURNS CASUALTIES
}

\author{
Major ANTONY F. WALLACE, F.R.C.S., R.A.M.C.(V) \\ 217th (Eastern) General Hospital, R.A.M.C.(V) *
}

ON the 6th February, 1966, at the D.D.M.S. Annual Exercise at Hounslow, Territorial R.A.M.C. officers and men and Q.A.R.A.N.C. officers of the 17th (London) General Hospital, R.A.M.C. (T.A.) presented a "Burns Demonstration". Those who took part are now members of the 217th (Eastern) General Hospital, R.A.M.C. (V). As a result of preparations for that demonstration and subsequent discussion two new facets of R.A.M.C. training appear (to the author) to require further development. Firstly, the sorting of burns casualties in a mass casualty context, since, undoubtedly, a relatively small number of extensively burnt patients-fifty, for example-would currently overwhelm the resources of any hospital, whether civilian or military. Secondly, the training of R.A.M.C. orderlies in the routine care of burnt patients treated by the exposure method, to be called burns nursing orderly drill.

Suggestions for administration and treatment included in this paper should be considered alongside the clinical aspects of patient care such as were described in this Journal under the title of "Burns. The first five days in the treatment of mass casualties" (Battle, 1958). It is hoped that this paper may cause further discussion to take place on the treatment of mass burns casualties.

\section{Surgical facts}

In both military and civilian circumstances, when any considerable number of burns casualties require emergency treatment, a modification of the long established practice of triage can be used in sorting. Since any necessary life saving treatment must be started within eight hours of the burning, the casualty must be correctly assessed when first seen. Fortunately, all the data needed to effect clinical and administrative grouping can be obtained by a specially trained intelligent nursing orderly, with a degree of accuracy fully acceptable in the difficult conditions envisaged. He works most productively when teamed with a clerk.

Inevitably, certain patients die because of their burns however quickly and correctly treatment is given, while at the other end of the clinical scale the trivial burn needs no particular treatment. Between these two extremes there is every degree of possible risk of death. Provided that the burns casualty is given sufficient food and fluids his (or equally hers, there is no significant sex difference) expectation of survival varies with age, the proportion of the skin surface burnt, and the presence of additional trauma such as burns of the resperatory passages, fractures, soft tissue injuries and irradiation damage. Except in rare circumstances it is impossible to determine the depth of a burn during the first ten days after burning. In the context of mass casualties the absence of an early diagnosis of depth is relatively unimportant since the depth of a burn, unless it is superficial as is sunburn, does not greatly alter the chance of death occurring during the first ten days. Nevertheless, a history of the circumstances of the burning may enable an informed guess to be made as the probable depth of the damage. Later, when definitive local treatment is being planned (Wallace, 1966), burnt areas are classified according to that which is both the earliest and the most modern criterion of depth (Forage, 1963), that is into areas of partial thickness and of full thickness skin destruction.

* Also Consultant Plastic Surgeon to St. Bartholomew's Hospital, London. 


\section{In Reception}

When taking the history in Reception the burns nursing orderly records five groups of facts:-(1) Patient's name, rank, number, unit, etc. (2) Patient's age. (3) The time and date at which he (the orderly) makes his examination (see below). (4) The time and date of burning. (5) The immediate cause of the burn.

At the subsequent examination in Reception the burns orderly records a further five facts:-(6) Patient's personal dosimeter reading. (7) Patient's pulse rate; this is useful later to gauge clinical progress. (8) Whether or not the patient's face is burnt. (9) The percentage surface area of the body burnt. The simple " rule of nines" is understood easily; it is in its application that the specialised training of the burns orderly particularly demonstrates its value. (10) The presence of additional injuries such as lacerations and fractures.

The patient's chance of survival, his personal prognosis, is predicted from these data which, it is proper to emphasise have all been collected by a specially trained burns mursing orderly.

Table I

Anticipated percentage mortality under ideal civilian conditions of treatment

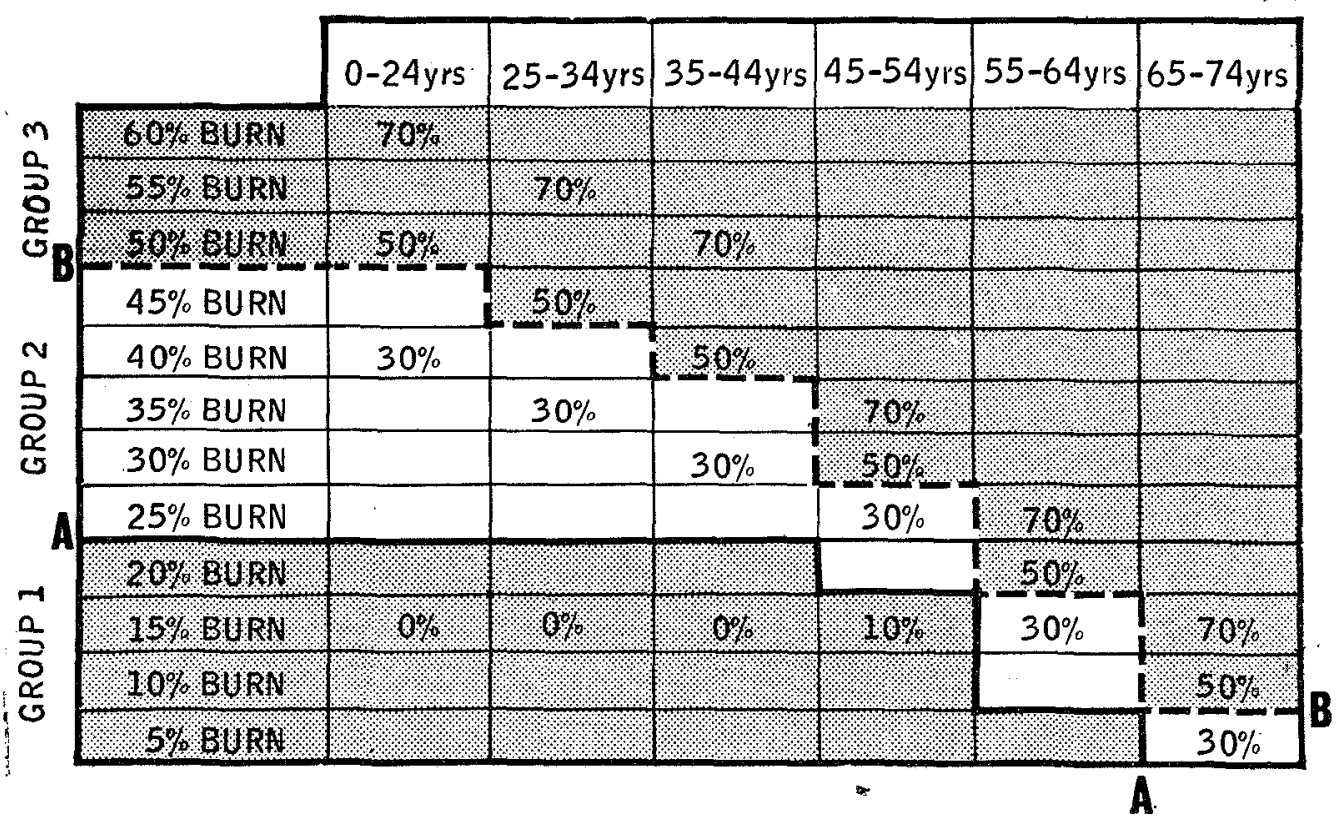

Note that there would be a disproportionately large loss of Senior Officers and NCOs, because of the age factor, if these figures were applied to a military mass casualty situation.

Table I, constructed from the data of Bull and Fisher (1954), gives the expectation of death for civilians of differing ages for different percentage body area burns, all of whom were treated a few at a time and with minimal delay in ideal hospital circumstances. In Group 1 below Line A (an estimated boundary selected by the author, as is Line B), 
are the patients of whom most would have lived without specific treatment. Line B divides most of those who lived (below Line B) from Group 3 patients (above Line B) most of whom died despite the best treatment. Facts (2) and (9) recorded in Reception enable the " ideal " survival chance for the uncomplicated case to be read off the Table, and the patient to be placed in the correct group. It is vital to appreciate that this "ideal" figure applies only to casualties treated in ideal circumstances. If the patient is placed in Group 2 (between Lines A and B) urgent treatment by doctors is essential.

Additional adverse factors apparent from other facts recorded by the orderly worsen the "ideal" chance of survival. Three examples may be considered:-A delay of more than eight hours between the burning and the opportunity of receiving specific treatment (facts (3) and (4)). A probable respiratory passages burn (facts (5) and (8)) as can follow an explosion or fire in a confined space, particularly if associated with loss of consciousness. Additional major injuries (facts (6) and (10)).

Such major additional adverse factors move the patient up a group, from Group 1 to Group 2, or from Group 2 to Group 3.

\section{Sorting by available treatment potential}

A non-commissioned officer (N.C.O.) could be trained to use the data to determine the prognosis, and with it the worthwhileness (in a statistical life-saving and not a moral sense) of ordering specific treatment. However, an N.C.O. should never be given this task because, and this is the nub of the problem in the context of mass casualties, this sorting into treatment groups will be governed absolutely by the available treatment potential.

A command decision to over-rule the clinical implications of the "ideal " figure, because of inadequate treatment facilities, would inevitably condemn many to die. Such a calculated raising of the standard required to qualify for treatment would be ordered only by a most senior medical officer having overall knowledge of the care the casualty will, not should, get. If conditions were very bad and numbers of casualties large, Group 2 would disappear and triage would yield two groups only, the living and the dying. Alternately, and this is a highly likely situation, facilities would be available to treat adequately only a small proportion of the casualties in Group 2. Within this group patients for treatment would have to be selected on grounds other than clinical, for example, military, political or eugenic. In fairness to medical officers liable to be involved in such a situation each must hold a (confidential) list of priority personnel and must have been ordered to adhere to that list. In the unhappy circumstances visualised the decisions must not be left to the individual medical officer's conscience.

\section{Outline of treatment}

It is visualised that casualties will be held in halls, tents and in the open. Group 1 contains those patients most of whom will survive but who need burns nursing orderly drill (see below). Group 2 contains those patients most of whom will survive if given urgent treatment by doctors in addition to burns nursing orderly drill. Group 3 contains those who are dying.

The requirements for the above groups may be listed briefly as follows:-

Groups 1 and 3. Deck chairs, stretchers, lilos, mattresses, newspapers on the fioor. Warm, ventilated accommodation. Mix sexes, ranks, civilian and service casualties. 
Groups 1 and 2. Need burns nursing orderly drill every four hours and which can be carried out on an "assembly line" system:-Oral fluids, including some saline. Passage of Ryle's tubes. Recording intake/output (i.e. cupfulls/acts of micturition). Lond acting penicillin, $2 \mathrm{ml}$ I.M. (once only). Chloramphenicol ointment for eyes and lips. Chloramphenicol powder in sprinklers for exposed burns, all equipment disposable. Food.

Group 2. Proper bed in hospital. Physicians, surgeons, and State Registered Nurses. Transfusion Teams (electrolytes more than blood (Miller, 1965)). Special dressings (Kohn, 1963 and 1967). Morphia, pethidine, chlorpromazine. Skin grafting after ten days i.e. evacuation in ten days. Three months and longer in a base hospital.

\section{Acknowledgements}

I wish to thank my commanding officer, Colonel T. W. A. Glenister, T.D., D.Sc., Ph.D., M.B., B.S., of the Volunteers, both for his valuable constructive criticisms and for permission to submit this paper for publication. The table was drawn by the Department of Medical Illustration of St. Batholomew's Hospital, London.

\section{REFERENCES}

Battle, R. J. (1958). J. roy. Army med. Cps. 104, 203.

BULL, J. P. and FISHER, A. J. (1954). Ann. Surg. 139, 269.

FoRAGE, A. V. (1963). Brit. J. plast. Surg. 16, 239.

KoHN, J. (1963). J. roy. Army med. Cps. 109, 199.

KoHN, J. (1967). J. roy. Army med. Cps. 113, 46.

MrleR, R. W. (1965). J. roy. Army med. Cps. 111, 3.

WALlaCE, A. F. (1966). Brit. J. plast. Surg. 19, 161. 